\title{
Nodulação, aspectos bioquímicos, crescimento e produtividade do feijoeiro em função da aplicação de bioestimulante ${ }^{1}$
}

\section{Nodulation, biochemical aspects, growth and yield of common bean according biostimulant application}

\author{
Adriana Queiroz de Almeida ${ }^{2 *}$; Rogério Peres Soratto \\ Fernando Broetto ${ }^{4}$; Ana Catarina Cataneo ${ }^{4}$
}

\begin{abstract}
Resumo
A utilização de bioestimulantes pode alterar o desenvolvimento e o crescimento vegetal, porém, a ação dos mesmos pode ser variável conforme o estádio de desenvolvimento da planta. Objetivou-se avaliar o efeito de formas e épocas de aplicação de um bioestimulante (citocinina, ácido indolbutírico e ácido giberélico) na nodulação, alguns aspectos bioquímicos, crescimento e produtividade do feijoeiro cultivar Pérola. Os tratamentos foram: Testemunha (sem aplicação); TS - $250 \mathrm{~mL} \mathrm{ha}^{-1}$ em tratamento de semente (TS); $\mathrm{V}_{4}-250 \mathrm{~mL}^{-1}$ via pulverização foliar em $\mathrm{V}_{4} ; \mathrm{R}_{5}-250 \mathrm{~mL} \mathrm{ha}^{-1}$ via pulverização foliar em $\mathrm{R}_{5} ; \mathrm{TS}+\mathrm{V}_{4}-250 \mathrm{~mL} \mathrm{ha}^{-1} \mathrm{em} \mathrm{TS}+250 \mathrm{~mL} \mathrm{ha}^{-1} \mathrm{em} \mathrm{V}_{4} ; \mathrm{TS}+\mathrm{R}_{5}-250 \mathrm{~mL} \mathrm{ha}^{-1} \mathrm{em} \mathrm{TS}+250$ $\mathrm{mL} \mathrm{ha}^{-1} \mathrm{em} \mathrm{R}_{5} ; \mathrm{V}_{4}+\mathrm{R}_{5}-250 \mathrm{~mL} \mathrm{ha}^{-1} \mathrm{em} \mathrm{V}_{4}+250 \mathrm{~mL} \mathrm{ha}^{-1} \mathrm{em} \mathrm{R}_{5}$ e TS $+\mathrm{V}_{4}+\mathrm{R}_{5}-250 \mathrm{~mL} \mathrm{ha}^{-1} \mathrm{em} \mathrm{TS}+$ $250 \mathrm{~mL} \mathrm{ha}^{-1} \mathrm{em} \mathrm{V}_{4}+250 \mathrm{~mL} \mathrm{ha}^{-1} \mathrm{em} \mathrm{R}_{5}$. A aplicação do bioestimulante via foliar na fase vegetativa $\left(\mathrm{V}_{4}\right)$ ou início da reprodutiva $\left(\mathrm{R}_{5}\right)$ proporciona incrementos na nodulação, no crescimento radicular, no conteúdo de açúcares solúveis e aminoácidos totais e na atividade da nitrato redutase, porém, não interfe no crescimento da parte aérea e na produtividade da cultura do feijão.
\end{abstract}

Palavras-chave: Phaseolus vulgaris, regulador vegetal, nitrato redutase, crescimento radicular

\begin{abstract}
The use of biostimulants can alter plant growth and development, but the action of they may be varied according to the stage of development of the plant. The aim was to evaluate the effects of forms and times of a biostimulant (cytokinin, indolebutyric acid, and gibberellic acid) application on nodulation, some biochemical aspects, growth and yield of common bean cultivar Pérola. The treatments were: Control (without application); TS - $250 \mathrm{~mL} \mathrm{ha}^{-1}$ seed treatment; $\mathrm{V}_{4}-250 \mathrm{~mL}^{-1}$ foliar spray in $\mathrm{V}_{4}$ stage; $\mathrm{R}_{5}-250 \mathrm{~mL} \mathrm{ha}^{-1}$ foliar spray in $\mathrm{R}_{5}$ stage; $\mathrm{TS}+\mathrm{V}_{4}-250 \mathrm{~mL} \mathrm{ha-1}{ }^{-1}$ in $\mathrm{TS}+250 \mathrm{~mL} \mathrm{ha}^{-1}$ in $\mathrm{V}_{4}$; $\mathrm{TS}+\mathrm{R}_{5}$ $-250 \mathrm{~mL} \mathrm{ha}^{-1}$ in TS $+250 \mathrm{~mL} \mathrm{ha}^{-1}$ in $\mathrm{R}_{5} ; \mathrm{V}_{4}+\mathrm{R}_{5}-250 \mathrm{~mL} \mathrm{ha}^{-1}$ in $\mathrm{V}_{4}+250 \mathrm{~mL} \mathrm{ha}^{-1}$ in $\mathrm{R}_{5}$, and $\mathrm{TS}+\mathrm{V}_{4}+\mathrm{R}_{5}$ $-250 \mathrm{~mL} \mathrm{ha}^{-1}$ in TS $+250 \mathrm{~mL} \mathrm{ha}^{-1}$ in $\mathrm{V}_{4}+250 \mathrm{~mL} \mathrm{ha}^{-1}$ in $\mathrm{R}_{5}$. The foliar biostimulant application in the vegetative $\left(\mathrm{V}_{4}\right)$ or early reproductive phase $\left(\mathrm{R}_{5}\right)$ increases nodulation, root growth, content of soluble sugars, content of total amino acid and nitrate reductase activity, however, does not interfere with shoot growth and grain yield of common bean.
\end{abstract}

Key words: Phaseolus vulgaris, plant regulator, nitrate reductase, root growth

${ }^{1}$ Parte da Tese de Doutorado da primeira autora, apresentada à Faculdade de Ciências Agronômicas, FCA, Universidade Estadual Paulista, UNESP, Botucatu, SP.

2 Pós-Doutoranda em Biologia Molecular na Universidade Federal do Recôncavo da Bahia, UFRB, Cruz das Almas, BA. E-mail: adrianaq_almeida@yahoo.com.br

3 Prof. Adjunto do Dept ${ }^{\circ}$ de Produção e Melhoramento Vegetal, FCA, UNESP, Botucatu, SP. Bolsista de produtividade em pesquisa do CNPq. E-mail: soratto@fca.unesp.br

${ }^{4}$ Profs. Adjunto do Dept ${ }^{\circ}$ de Química e Bioquímica, Instituto de Biociências, UNESP, Botucatu, SP. E-mail: broetto@ibb.unesp. br; acataneo@ibb.unesp.br

* Autor para correspondência 


\section{Introdução}

No Brasil, o feijão (Phaseolus vulgaris L.) é uma das principais culturas, pois está distribuído por todo o território nacional, apresentando boa adaptação às diversidades climáticas do país. $\mathrm{O}$ feijoeiro tem sistema radicular superficial e na floração mais de $83 \%$ da biomassa radicular concentra-se na camada de 0-20 cm do solo (INFORZATO; MIYASAKA, 1963; SILVA et al., 2009). Além disso, apresenta ciclo curto, variando de 75 a 110 dias (AIDAR; KLUTHCOUSKI, 2009).

Neste contexto, o emprego de estratégias que favoreçam o crescimento rápido torna-se premente, principalmente no período inicial da vida da planta e os bioestimulantes podem, em função da sua composição, concentração e proporção das substâncias, incrementar o crescimento e desenvolvimento vegetal, estimulando a divisão celular, diferenciação e o alongamento das células, favorecer o equilíbrio hormonal da planta, podendo também aumentar a absorção e a utilização de água e dos nutrientes pelas plantas (VIEIRA; CASTRO, 2001; FANCELLI; TSUMANUMA, 2007). Dessa forma, a raiz é um dreno a ser priorizado, principalmente pelo fato de que em regiões tropicais a água e nutrientes são, geralmente, fatores limitantes à produtividade das culturas.

Estudos também têm comprovado que a auxina age diretamente na formação de nódulos em leguminosas (MATHESIUS, 2008) e existem muitas formas pela qual a bactéria simbionte poderia alterar a raiz e o desenvolvimento do nódulo através do envolvimento da auxina (PERET et al., 2007; SPAEPEN; VANDERLEYDEN; REMANS, 2007) e, tanto a citocinina (GONZALEZ-RIZZO; CRESPI; FRUGIER, 2006; MURRAY et al., 2007) quanto o ácido giberélico (LIEVENS et al., 2005) também podem estar relacionados com o processo de nodulação. Assim, a aplicação de biostimulante, que contem estas substâncias, poderia melhorar o crescimento radicular e aumentar a nodulação no feijoeiro. Porém, Klahold et al. (2006) observaram redução de 41,2\% no número de nódulos na soja pulverizada com solução de $0,225 \mathrm{~mL} \mathrm{~L}^{-1}$ do bioestimulante, contendo citocinina, ácido indolbutírico e ácido giberélico.

$\mathrm{O}$ bioestimulante pode ser utilizado tanto no tratamento de sementes como no sulco de semeadura e/ou em pulverizações foliares. Na cultura da soja, Klahold et al. (2006), Ávila et al. (2008), Bertolin et al. (2010), Albrecht et al. (2011) e Albrecht et al. (2012) verificaram incremento no número de vagens por planta e na produtividade de grãos de soja, tanto em aplicação via sementes quanto via foliar, em estádios vegetativos e reprodutivos. $\mathrm{Na}$ cultura do algodão, Albrecht et al. (2009), também observaram aumento na massa média do capulho e na produtividade de algodão em caroço com o uso do mesmo bioestimulante tanto via tratamento de semente quanto via foliar. Já Dario et al. (2005) observaram que a utilização do bioestimulante no tratamento de sementes, em pulverização dirigida na linha de semeadura, sobre as sementes, e em pulverização foliar, não apresentou influência significativa sobre o número de vagens por plantas e a produtividade de grãos da cultura da soja. Baldo et al. (2009) também verificaram que a aplicação do bioestimulante via tratamento de sementes e via pulverização foliar não interferiu no desenvolvimento da parte aérea e do sistema radicular de plantas de algodão.

Castro et al. (2004) observaram que a aplicação foliar de bioestimulante aumentou a massa de vagens e a massa de grãos do feijoeiro cultivar IAC-Carioca Tybatã, mas não observaram efeitos significativos para o número de vagens por planta. No entanto, Alleoni, Bosqueiro e Rossi (2000) não observaram efeito do bioestimulante via semente ou foliar na produtividade do feijoeiro. Silva et al. (2009) constataram que quando aplicaram o produto durante o período de floração e pós-floração, houve aumento no número de vagens por planta, porém, que não refletiu em aumento da produtividade de grãos. Ávila et al. (2010) verificaram que aplicações foliares de bioestimulante, tanto no estádio 
vegetativo $\left(\mathrm{V}_{4}\right)$ quanto no estádio reprodutivo $\left(\mathrm{R}_{5}\right)$, não proporcionaram alteração no crescimento e produtividade do feijoeiro. Já Cobucci e Wruck (2005) observaram incremento de 30\% na produtividade quando aplicaram o bioestimulante no estádio $\mathrm{R}_{5}$. Abrantes et al. (2011) constataram que aplicação do bioestimulante no estádio reprodutivo $\left(\mathrm{R}_{5}\right)$ porporcionou maior número de grãos por planta e produtividade de grãos do feijoeiro do que a aplicação no estádio vegetativo $\left(\mathrm{V}_{4}\right)$. Contudo, os resultados encontrados na literatura ainda são muito contraditórios, variando de acordo com a forma e época de aplicação, especialmente na cultura do feijão. Além disso, poucos estudos investigaram o efeito do bioestimulante na nodulação, crescimento radicular e aspectos bioquímicos de plantas de feijão.

Objetivou-se avaliar o efeito de formas e épocas de aplicação de bioestimulante (citocinina, ácido indolbutírico e ácido giberélico) na nodulação, em alguns aspectos bioquímicos, no crescimento e na produtividade do feijoeiro cultivar Pérola.

\section{Material e Métodos}

O experimento foi realizado em casa de vegetação localizada no Município de Botucatu, SP (22 $51^{\circ}$ ' latitude Sul, 48 $26^{\prime}$ longitude Oeste e altitude de 740 m). Para tanto, uma porção de solo classificado como Latossolo Vermelho distroférrico, de textura média (630, 40 e $330 \mathrm{~g} \mathrm{~kg}^{-1}$ de areia, silte e argila, respectivamente) foi peneirada (peneira com malha de 4,0 mm). Uma amostra foi submetida à análise química, cujos resultados são apresentados na Tabela 1. Foi aplicado no solo calcário dolomítico (PRNT $=91,5 \%$ ), na dose $2,68 \mathrm{~g} \mathrm{dm}^{-3}$, objetivando elevar a saturação por bases à $70 \%$ e foi incubado com umidade de aproximadamente $80 \%$ da capacidade de retenção de água, por um período de 50 dias. Após a incubação, o solo recebeu $200 \mathrm{mg} \mathrm{dm}^{-3}$ de $\mathrm{P}$ (superfosfato simples) e $150 \mathrm{mg} \mathrm{dm}^{-3}$ de $\mathrm{K}$ (cloreto de potássio), $32 \mathrm{mg} \mathrm{dm}^{-3}$ de $\mathrm{N}$ (nitrato de amônio) e $58 \mathrm{mg} \mathrm{dm}^{-3}$ de FTE-BR12 (9,0\% de Zn, 3,0\% de Fe, 2,0 de $\mathrm{Mn}, 1,8 \%$ de $\mathrm{B}, 0,8 \%$ de $\mathrm{Cu}$ e $0,1 \%$ de $\mathrm{Mo}$ ). Após isso, o solo foi acomodado em vasos com capacidade de $12 \mathrm{dm}^{3}$. Por ocasião da semeadura do feijão, ou seja, cinco dias após a incorporação dos fertilizantes, uma amostra de solo foi coletada e submetida à análise química (Tabela 1).

Tabela 1. Características químicas do solo utilizado no experimento antes da correção (original) e por ocasião da semeadura do feijão.

\begin{tabular}{|c|c|c|c|c|c|c|c|c|c|c|}
\hline Época & $\mathrm{pH}\left(\mathrm{CaCl}_{2}\right)$ & $\begin{array}{c}\text { M.O. } \\
\left(\mathrm{g} \mathrm{kg}^{-1}\right)\end{array}$ & $\begin{array}{c}\mathrm{P}_{\text {resina }} \\
\left(\mathrm{mg} \mathrm{dm}^{-3}\right)\end{array}$ & $\mathrm{H}+\mathrm{Al}$ & $\mathrm{Al}$ & \multicolumn{2}{|c|}{$\left(\mathrm{mmol}_{c} \mathrm{dm}^{-3}\right)$} & $\mathrm{Mg}$ & CTC & $\begin{array}{c}\mathrm{V} \\
(\%)\end{array}$ \\
\hline Original & 4,1 & 18,0 & 3,0 & 72,0 & 14,0 & 0,2 & 2,0 & 1,0 & 75,2 & 4 \\
\hline Semeadura & 5,5 & 19,0 & 80,0 & 28,9 & 1,0 & 3,6 & 45,0 & 17,0 & 95,5 & 69 \\
\hline & $\mathrm{S}-\mathrm{SO}_{4}{ }^{2-}$ & Boro & \multicolumn{3}{|c|}{$\begin{array}{l}\text { Cobre } \\
\qquad\left(\mathrm{mg} \mathrm{dm}^{-3}\right)\end{array}$} & & \multicolumn{2}{|c|}{ Manganês } & \multicolumn{2}{|c|}{ Zinco } \\
\hline $\begin{array}{r}\text { Original } \\
\text { Semeadura }\end{array}$ & $\begin{array}{c}11,0 \\
176,0\end{array}$ & $\begin{array}{l}0,13 \\
0,65\end{array}$ & & & & & & & & \\
\hline
\end{tabular}

Fonte: Elaboração dos autores. 
O delineamento experimental adotado foi de blocos completos ao acaso, com quatro repetições. Os tratamentos foram constituídos por oito formas de aplicação do bioestimulante e caracterizados por: Testemunha (sem aplicação); TS - $250 \mathrm{~mL} \mathrm{ha}^{-1}$ em tratamento de semente (TS); $\mathrm{V}_{4}-250 \mathrm{~mL} \mathrm{ha}^{-1}$ via foliar no estádio $\mathrm{V}_{4}$ (FERNÁNDEZ; GEPTS; LÓPES, 1986); $\mathrm{R}_{5}-250 \mathrm{~mL} \mathrm{ha}^{-1}$ via foliar no estádio $\mathrm{R}_{5} ; \mathrm{TS}+\mathrm{V}_{4}-250 \mathrm{~mL} \mathrm{ha}^{-1} \mathrm{em} \mathrm{TS}+250 \mathrm{~mL}$ $\mathrm{ha}^{-1} \mathrm{em} \mathrm{V}_{4}$; TS+R $\mathrm{R}_{5}-250 \mathrm{~mL} \mathrm{ha}^{-1} \mathrm{em} \mathrm{TS}+250 \mathrm{~mL}$ $\mathrm{ha}^{-1}$ em $\mathrm{R}_{5} ; \mathrm{V}_{4}+\mathrm{R}_{5}-250 \mathrm{~mL} \mathrm{ha}^{-1} \mathrm{em} \mathrm{V}_{4}+250 \mathrm{~mL}$ $\mathrm{ha}^{-1}$ em $\mathrm{R}_{5}$ e TS $+\mathrm{V}_{4}+\mathrm{R}_{5}-250 \mathrm{~mL} \mathrm{ha}^{-1} \mathrm{em} \mathrm{TS}+250$ $\mathrm{mL} \mathrm{ha}^{-1} \mathrm{em} \mathrm{V}_{4}+250 \mathrm{~mL} \mathrm{ha}^{-1} \mathrm{em} \mathrm{R}_{5}$.

Utilizou-se, para a preparação dos tratamentos, o bioestimulante comercial denominado Stimulate ${ }^{\circledR}$ (Stoller do Brasil, Cosmópolis, São Paulo, Brasil) que contém fitorreguladores e traços de sais minerais, sendo de composição variável, tendo como garantias: $0,009 \%$ de cinetina (citocinina), 0,005\% de ácido giberélico (giberelina), 0,005\% de ácido indolbutírico (auxina) e 99,981\% de ingredientes inertes (CASTRO, 1998). As sementes da cultivar Pérola receberam os tratamentos citados anteriormente com o bioestimulante na dose de $3 \mathrm{~mL} \mathrm{~kg}^{-1}$ de sementes e, posteriormente, foram inoculadas com Rhizobium tropici (estirpe Semia 4080, turfoso). A semeadura foi realizada após 30 minutos da aplicação do bioestimulante, para promover absorção do produto, utilizando-se oito sementes por vaso. $\mathrm{O}$ desbaste foi realizado cinco dias após a emergência (DAE), deixando-se três plantas por vaso. $\mathrm{O} \mathrm{N}$ em cobertura foi fornecido mediante cinco aplicações, utilizando-se $15 \mathrm{mg}$ $\mathrm{dm}^{-3}$ de $\mathrm{N}$ (sulfato de amônio), aos 8, 26 e 34 DAE e $18 \mathrm{mg} \mathrm{dm}^{-3}$ de $\mathrm{N}$ (uréia) aos 40 e 49 DAE. Também foram aplicados $40 \mathrm{mg} \mathrm{dm}^{-3}$ de $\mathrm{K}$ (cloreto de potássio), aos 40 e 49 DAE.

A irrigação foi realizada periodicamente, avaliando-se a necessidade através da pesagem dos vasos, colocando-se a quantidade suficiente para elevar a $100 \%$ da capacidade de retenção de água sempre que o nível atingisse $80 \%$ desta. A máxima capacidade de retenção foi previamente determinada e a quantidade estabelecida inicialmente foi de 1,5 L de água por vaso. As temperaturas médias registradas nos meses de março, abril e maio de 2009 (período de execução desse experimento) foram $24,3{ }^{\circ} \mathrm{C}, 22,5^{\circ} \mathrm{C}$ e $20,8^{\circ} \mathrm{C}$, respectivamente.

Aos 23 DAE as plantas atingiram o estádio $\mathrm{V}_{4}$ ( $3^{\mathrm{a}}$ folha trifoliolada totalmente expandida). $\mathrm{O}$ estádio $\mathrm{R}_{5}$ (início da fase reprodutiva/préflorescimento) foi atingido aos 30 DAE e o estádio $\mathrm{R}_{6}$ (pleno florescimento) aos 38 DAE. As plantas de feijão atingiram a maturação fisiológica (estádio $\mathrm{R}_{9}$ ) 78 DAE. As avaliações foram realizadas de acordo com cada tratamento, ou seja, no estádio $\mathrm{V}_{4}$ foram analisados os tratamentos testemunha e TS, no estádio $\mathrm{R}_{5}$ os tratamentos testemunha, $\mathrm{TS}, \mathrm{V}_{4}$ e $\mathrm{TS}+\mathrm{V}_{4}$. No estádio $\mathrm{R}_{6}$ e final do ciclo todos os tratamentos foram avaliados. Algumas avaliações realizadas necessitaram de desmontagem dos vasos, portanto, houve a necessidade de se instalar, inicialmente, uma maior quantidade de repetições, visando manter, ao final, após as avaliações destrutivas, o número de repetições adequadas a se proceder a análise estatística. Para os tratamentos testemunha e TS foram instalados 16 vasos de cada um. Para os tratamentos $\mathrm{V}_{4}$ e $\mathrm{TS}+\mathrm{V}_{4}$ foram instalados 12 vasos de cada um e para os demais tratamentos, foram instalados inicialmente 8 vasos cada um, totalizando-se inicialmente 88 vasos.

Nos estádios $V_{4}, R_{5}$ e $R_{6}$ foram avaliados: massas de matéria seca da parte aérea, raiz e total, índice relativo de clorofila, comprimento do caule, número de nódulos por planta, número de nós por planta, área foliar, avaliação do sistema radicular, atividade da nitrato redutase, determinação do conteúdo foliar de açúcares solúveis totais e conteúdo de aminoácidos totais.

O índice relativo de clorofila foi determinado através do medidor de clorofila SPAD 502 e a determinação da área foliar foi realizada em um integrador de área foliar de bancada LICOR modelo 3100C. A atividade da nitrato redutase foi determinada segundo o método descrito por Jaworski (1971). A determinação conteúdo foliar de açúcares solúveis totais seguiu a metodologia descrita por Dubois et al. (1956) e o conteúdo de aminoácidos totais foi determinado de acordo com Kabat e Mayer (1967). 
Para as avaliações do sistema radicular foi utilizado um scanner acoplado a um computador dotado do software WinRhyzo, que utiliza como princípio ativo a metodologia proposta por Tennant (1975). Neste equipamento foi determinado o comprimento ( $\mathrm{m}$ planta $\left.{ }^{-1}\right)$, a superfície $\left(\mathrm{cm}^{2}\right.$ planta $\left.^{-1}\right)$ e o diâmetro médio radicular $(\mathrm{mm})$. Após essas avaliações as amostras foram secas em estufa a 65 ${ }^{\circ} \mathrm{C}$, por 72 horas, e posteriormente foi determinada a massa da matéria seca radicular (g planta $\left.{ }^{-1}\right)$. Número de vagens por planta, número de grãos por vagem, massa de 100 grãos, massa dos grãos por planta e teor de proteína nos grãos foram avaliados no final do ciclo.

Os dados foram submetidos à análise de variância e as médias comparadas pelo teste Tukey a 5\% de probabilidade, utilizando o programa Sisvar (FERREIRA, 2011).

\section{Resultados e Discussão}

A aplicação do bioestimulante não influenciou significativamente a massa de matéria seca da parte aérea, de raízes e total, em nenhum dos estádios avaliados (Tabela 2). Alleoni, Bosqueiro e Rossi (2000) e Vieira e Castro (2003) também não verificaram efeito da aplicação de bioestimulante, via tratamento de semente ou foliar, no acúmulo de matéria seca da parte aérea do feijoeiro no florescimento. De acordo com Castro et al. (2008), a aplicação do bioestimulante via semente não alterou o acúmulo de matéria seca de raízes e da parte aérea na fase inicial do desenvolvimento de plantas de soja. Baldo et al. (2009) também não verificaram efeito da aplicação do bioestimulante via tratamento de sementes e via pulverização foliar no acúmulo de matéria seca na parte aérea e no sistema radicular de plantas de algodão.

Tabela 2. Massa de matéria seca de folha, caule, raiz e total do feijoeiro em função aplicação do bioestimulante, nos estádios $\mathrm{V}_{4}, \mathrm{R}_{5}$ e $\mathrm{R}_{6}$.

\begin{tabular}{lccc}
\hline Tratamento & $\begin{array}{c}\text { Matéria seca parte aérea } \\
\left(\text { g planta }^{-1}\right)\end{array}$ & $\begin{array}{c}\text { Matéria seca de raiz } \\
\left(\text { g planta }^{-1}\right)\end{array}$ & $\begin{array}{c}\text { Matéria seca total } \\
\left(\mathrm{g} \mathrm{planta}^{-1}\right)\end{array}$ \\
\hline Testemunha & $2,4 \mathrm{a}$ & ${\text { Estádio } \mathrm{V}_{4}\left(3^{\mathrm{a}} \text { folha totalmente expandida }\right)}_{1,0 \mathrm{a}}$ & $3,4 \mathrm{a}$ \\
$\mathrm{TS}$ & $2,6 \mathrm{a}$ & $1,0 \mathrm{a}$ & $3,6 \mathrm{a}$ \\
\hline $\mathrm{CV}(\%)$ & 4,7 & 6,0 & 2,9 \\
\hline & & Estádio $_{5}$ (início do surgimento de botões florais $)$ \\
Testemunha & $5,4 \mathrm{a}$ & $1,6 \mathrm{a}$ & $7,0 \mathrm{a}$ \\
$\mathrm{TS}$ & $4,9 \mathrm{a}$ & $1,4 \mathrm{a}$ & $6,5 \mathrm{a}$ \\
$\mathrm{V}_{4}$ & $4,7 \mathrm{a}$ & $1,6 \mathrm{a}$ & $6,3 \mathrm{a}$ \\
$\mathrm{TS}+\mathrm{V}_{4}$ & $5,2 \mathrm{a}$ & $1,6 \mathrm{a}$ & $6,8 \mathrm{a}$ \\
\hline $\mathrm{CV}(\%)$ & 7,7 & 13,1 & 7,6 \\
\hline & & & \\
Testemunha & $7,1 \mathrm{a}$ & $1,6 \mathrm{a}$ & $8,7 \mathrm{a}$ \\
$\mathrm{TS}$ & $7,5 \mathrm{a}$ & $1,8 \mathrm{a}$ & $9,3 \mathrm{a}$ \\
$\mathrm{V}_{4}$ & $8,1 \mathrm{a}$ & $1,7 \mathrm{a}$ & $9,8 \mathrm{a}$ \\
$\mathrm{R}_{5}$ & $7,7 \mathrm{a}$ & $1,7 \mathrm{a}$ & $9,5 \mathrm{a}$ \\
$\mathrm{TS}+\mathrm{V}_{4}$ & $7,0 \mathrm{a}$ & $1,4 \mathrm{a}$ & $8,4 \mathrm{a}$ \\
$\mathrm{TS}+\mathrm{R}_{5}$ & $7,2 \mathrm{a}$ & $1,6 \mathrm{a}$ & $8,8 \mathrm{a}$ \\
$\mathrm{V}_{4}+\mathrm{R}_{5}$ & $7,1 \mathrm{a}$ & $1,5 \mathrm{a}$ & $8,6 \mathrm{a}$ \\
TS $+\mathrm{V}_{4}+\mathrm{R}_{5}$ & $7,4 \mathrm{a}$ & $1,7 \mathrm{a}$ & $9,1 \mathrm{a}$ \\
\hline $\mathrm{CV}(\%)$ & 11,4 & 10,3 & 10,1 \\
\hline
\end{tabular}

Médias seguidas da mesma letra na coluna, em cada época de avaliação, não diferem estatisticamente entre si pelo teste de Tukey a 5\% de probabilidade. Os tratamentos foram: Testemunha (sem aplicação de bioestimulante), TS (tratamento de semente), $\mathrm{V}_{4}$ (pulverização em $\mathrm{V}_{4}$ ), $\mathrm{R}_{5}$ (pulverização em $\mathrm{R}_{5}$ ), $\mathrm{TS}+\mathrm{V}_{4}$ (tratamento de semente + pulverização em $\mathrm{V}_{4}$ ), $\mathrm{TS}+\mathrm{R}_{5}($ tratamento de semente + pulverização em $\mathrm{R} 5$ ), $\mathrm{V}_{4}+\mathrm{R}_{5}$ (pulverização em $\mathrm{V}_{4}+$ pulverização em $\mathrm{R}_{5}$ ) e $\mathrm{TS}+\mathrm{V}_{4}+\mathrm{R}_{5}$ (tratamento de semente + pulverização em $\mathrm{V}_{4}$ e $\mathrm{R}_{5}$ ).

Fonte: Elaboração dos autores. 
O número de nódulos por planta, avaliado nos estádios $V_{4}$ e $R_{5}$, não foi influenciado pela aplicação do bioestimulante (Tabela 3). Contudo, na avaliação realizada em $\mathrm{R}_{6}$ observou-se incremento desta variável, especialmente nos tratamentos que receberam aplicação do bioestimulante nos estádios $\mathrm{V}_{4}, \mathrm{R}_{5}, \mathrm{TS}+\mathrm{V}_{4}$ e $\mathrm{TS}+\mathrm{R}_{5}$. A pulverização foliar no estádio $\mathrm{V}_{4}$ proporcionou a maior média e esse valor foi $129,5 \%$ superior à testemunha. Existem muitas formas pela qual a bactéria simbionte poderia alterar a raiz e o desenvolvimento do nódulo através do envolvimento da auxina: via síntese da auxina pelo microsimbionte ou através da alteração da síntese desse hormônio (quebra, sinalização ou transporte) no hospedeiro (SPAEPEN; VANDERLEYDEN; REMANS, 2007; MATHESIUS, 2008). Mesmo em plantas não simbiontes, a síntese de auxina tem demonstrado promover o crescimento da bactéria, como cianobactérias, do gênero Frankia e do próprio Rhizobium (PERET et al., 2007; MATHESIUS, 2008). A exsudação de vários compostos produzidos pelas plantas estimula a síntese de auxina nas bactérias, assim, estas a sintetizam através do triptofano exsudado pelas raízes da plantas (KEFFORD; BROCKWELL; ZWAR, 1960). Ou ainda pela exsudação de flavonóides, em leguminosas, que estimulam a síntese do fator Nod, que também tem sido relacionado com a síntese da auxina nos Rhizobium sp. (THEUNIS et al., 2004; SPAEPEN; VANDERLEYDEN; REMANS, 2007). Esse processo é uma estratégia refinada do rizóbio para controlar o desenvolvimento da nodulação e também pode ser uma manipulação indireta no transporte da auxina ou seu retorno à planta hospedeira (MATHESIUS, 2008). Assim o fornecimento de auxina através do bioestimulante favoreceu a nodulação do feijoeiro.

$\mathrm{Na}$ avaliação em $\mathrm{V}_{4}$, foi verificado incremento significativo no índice relativo de clorofila no tratamento que recebeu aplicação do bioestimulante nas sementes (Tabela 3). A citocinina, presente na composição do produto, parece manter em alto nível a síntese de proteínas e enzimas, mantendo o vigor celular e processo metabólico de absorção e assimilação dos nutrientes, além disso, retarda a degradação de proteínas e clorofila (COLL et al., 2001). Contudo, em $R_{5}$ e $R_{6}$ não foram verificadas diferenças entre os tratamentos.

Foram encontrados resultados significativos para área foliar nas avaliações realizadas nos estádio $\mathrm{V}_{4}$ e $\mathrm{R}_{6}$ (Tabela 3). As plantas que receberam aplicação de bioestimulante nas sementes apresentaram área foliar média de $553,8 \mathrm{~cm}^{2}$ por planta, esse resultado corresponde a um incremento de 7,36\% em relação à testemunha (Tabela 3 ). Na avaliação realizada em $\mathrm{R}_{6}$, os tratamentos que receberam uma única aplicação de bioestimulante, seja em $\mathrm{V}_{4}$ ou em $\mathrm{R}_{5}$, apresentaram maiores médias de área foliar em relação ao tratamento que recebeu aplicação via tratamento de sementes e pulverização foliar em $R_{5}\left(T S+R_{5}\right)$, porém, sem diferir dos demais tratamentos, incluindo a testemunha. Campos et al. (2008) observaram aumento da área foliar quando aplicaram bioestimulante em plantas de soja aos 43, 74 e 105 dias após a semeadura. Já Klahold et al. (2006), observaram redução de 19,7\% nesta variável, com aplicação do bioestimulante nas sementes de soja e via foliar no estádio $\mathrm{R}_{2}$. Já Baldo et al. (2009) não observaram efeito da aplicação do bioestimulante, via tratamento de semente ou pulverização foliar, na área foliar do algodoeiro. O ácido indolbutírico (auxina), presente na composição do bioestimulante é responsável pelo alongamento da parede celular (essa é a resposta inicial dos tecidos vegetais às auxinas) e a cinetina (citocinina) participa ativamente dos processos de divisão e diferenciação celular (TAIZ; ZEIGER, 2009), além de estimular a divisão celular; a mistura de auxinas e de citocininas induz o início da diferenciação celular e dessa forma o bioestimulante pode agir no crescimento e desenvolvimento foliar (VIEIRA; CASTRO, 2001). Contudo, a resposta das plantas ao bioestimulante que contem estas substâncias pode variar em função de diversos fatores (ALBRECHT et al., 2012). 
Tabela 3. Número de nódulos por planta, número de nós por planta, comprimento do caule, índice relativo de clorofila e área foliar do feijoeiro, cultivar Pérola, em função da aplicação do bioestimulante, nos estádios $V_{4}, R_{5}$ e $R_{6}$.

\begin{tabular}{|c|c|c|c|c|c|}
\hline Tratamento & $\begin{array}{c}\text { № de nódulos/ } \\
\text { planta }\end{array}$ & $\begin{array}{c}\text { № de nós/ } \\
\text { planta }\end{array}$ & $\begin{array}{l}\text { Comprimento } \\
\text { do caule }(\mathrm{cm})\end{array}$ & $\begin{array}{l}\text { Índice relativo de } \\
\text { clorofila (SPAD) }\end{array}$ & $\begin{array}{c}\text { Área foliar }\left(\mathrm{cm}^{2}\right. \\
\left.\text { planta }^{-1}\right)\end{array}$ \\
\hline & \multicolumn{5}{|c|}{ Estádio $\mathrm{V}_{4}\left(3^{\mathrm{a}}\right.$ folha totalmente expandida $)$} \\
\hline Testemunha & $30,5 \mathrm{a}$ & $6,8 \mathrm{a}$ & $23,1 \mathrm{a}$ & $36,3 b$ & $515,8 b$ \\
\hline TS & $31,5 \mathrm{a}$ & $7,3 \mathrm{a}$ & $25,4 \mathrm{a}$ & $37,9 \mathrm{a}$ & $553,8 \mathrm{a}$ \\
\hline \multirow[t]{2}{*}{ CV $(\%)$} & 16,4 & 5,0 & 5,4 & 1,7 & 2,1 \\
\hline & \multicolumn{5}{|c|}{ Estádio $\mathrm{R}_{5}$ (início do surgimento de botões florais) } \\
\hline Testemunha & $117,0 \mathrm{a}$ & $9,5 \mathrm{a}$ & $69,6 \mathrm{ab}$ & $41,5 \mathrm{a}$ & $807,0 \mathrm{a}$ \\
\hline TS & $118,5 \mathrm{a}$ & $9,3 \mathrm{a}$ & $65,7 b$ & $40,9 \mathrm{a}$ & $783,6 a$ \\
\hline $\mathrm{V}_{4}$ & $113,6 a$ & $9,2 \mathrm{a}$ & $76,6 \mathrm{a}$ & $40,6 \mathrm{a}$ & $802,0 \mathrm{a}$ \\
\hline $\mathrm{TS}^{4}+\mathrm{V}_{4}$ & $124,3 \mathrm{a}$ & $9,6 \mathrm{a}$ & $65,5 b$ & $41,1 \mathrm{a}$ & $844,5 \mathrm{a}$ \\
\hline \multirow[t]{2}{*}{$\mathrm{CV}(\%)$} & 10,7 & 5,1 & 6,8 & 4,3 & 5,4 \\
\hline & \multicolumn{5}{|c|}{ Estádio $\mathrm{R}_{6}$ (florescimento pleno) } \\
\hline Testemunha & $93,7 \mathrm{c}$ & $10,7 \mathrm{a}$ & $99,4 \mathrm{a}$ & $38,2 a$ & $889,9 \mathrm{ab}$ \\
\hline $\mathrm{TS}$ & $150,4 \mathrm{~b}$ & $10,8 \mathrm{a}$ & $93,6 \mathrm{a}$ & $37,2 \mathrm{a}$ & $920,7 \mathrm{ab}$ \\
\hline $\mathrm{V}_{4}$ & $215,0 \mathrm{a}$ & $11,3 a$ & $101,6 a$ & $38,0 \mathrm{a}$ & $1002,4 a$ \\
\hline $\mathrm{R}_{5}^{4}$ & $182,0 \mathrm{ab}$ & $11,0 \mathrm{a}$ & $105,1 \mathrm{a}$ & $38,7 \mathrm{a}$ & $988,1 \mathrm{a}$ \\
\hline $\mathrm{TS}+\mathrm{V}_{4}$ & $164,4 \mathrm{ab}$ & $11,1 \mathrm{a}$ & $99,9 \mathrm{a}$ & $37,4 a$ & $943,1 \mathrm{ab}$ \\
\hline $\mathrm{TS}+\mathrm{R}_{5}^{4}$ & $167,8 \mathrm{ab}$ & $11,5 \mathrm{a}$ & $103,4 a$ & $37,3 \mathrm{a}$ & $841,4 b$ \\
\hline $\mathrm{V}_{4}+\mathrm{R}_{5}^{5}$ & $142,4 \mathrm{bc}$ & $10,6 \mathrm{a}$ & $91,1 \mathrm{a}$ & $37,3 \mathrm{a}$ & $951,6 \mathrm{ab}$ \\
\hline $\mathrm{TS}^{4}+\mathrm{V}_{4}^{5}+\mathrm{R}_{5}$ & $152,3 \mathrm{~b}$ & $11,4 \mathrm{a}$ & $97,4 \mathrm{a}$ & $36,2 \mathrm{a}$ & $934,9 \mathrm{ab}$ \\
\hline $\mathrm{CV}(\%)$ & 14,6 & 5,6 & 9,2 & 4,2 & 5,6 \\
\hline
\end{tabular}

Médias seguidas da mesma letra na coluna, em cada época de avaliação, não diferem estatisticamente entre si pelo teste de Tukey a $5 \%$ de probabilidade. Os tratamentos foram: Testemunha (sem aplicação de bioestimulante), TS (tratamento de semente), $\mathrm{V}_{4}$ (pulverização em $\mathrm{V}_{4}$ ), $\mathrm{R}_{5}$ (pulverização em $\mathrm{R}_{5}$ ), $\mathrm{TS}+\mathrm{V}_{4}$ (tratamento de semente + pulverização em $\mathrm{V}_{4}$ ), $T S+\mathrm{R}_{5}$ (tratamento de semente + pulverização em R5), $V_{4}+R_{5}$ (pulverização em $V_{4}+$ pulverização em $R_{5}$ ) e $T S+V_{4}+R_{5}$ (tratamento de semente + pulverização em $\mathrm{V}_{4}$ e $\mathrm{R}_{5}$ ).

Fonte: Elaboração dos autores.

O comprimento radicular não foi influenciado significativamente pela aplicação do bioestimulante nas avaliações realizadas em $\mathrm{V}_{4}$ e $\mathrm{R}_{5}$ (Tabela 4). Contudo, em $\mathrm{R}_{6}$ observou-se maior comprimento radicular do feijoeiro nos tratamentos que receberam aplicação do produto em $\mathrm{R}_{5}$, ou em $\mathrm{TS}+\mathrm{R}_{5}$; no entanto, sem diferirem do tratamento que recebeu aplicação em $\mathrm{TS}+\mathrm{V}_{4}$. Quando maior a concentração de auxina maior a taxa de crescimento do sistema radicular (KUDOYAROVA; FARKHUTDINOV; VESELOV, 1997). O ácido indolbutírico tem a capacidade de promover a formação de primórdios radiculares, por esse motivo tem sido utilizado para provocar e acelerar o enraizamento de estacas na propagação vegetativa de numerosas espécies vegetais, ou seja, esse regulador é utilizado para favorecer a rizogênese (COLL et al., 2001). Vieira e Castro (2003) não observaram efeitos consistes da aplicação de bioestimulante, via tratamento de sementes, no comprimento radicular de plantas de feijão e de trigo. Silva et al. (2009) também não observaram efeitos no crescimento radicular quando aplicaram a dose de $5 \mathrm{~mL} \mathrm{~kg}^{-1}$ de semente de feijão e, apesar de resultados não signficativos, eles relataram um efeito inibitório nesta variável. 
Tabela 4. Comprimento, superfície e diâmetro médio radicular do feijoeiro em função da aplicação do bioestimulante, nos estádios $\mathrm{V}_{4}, \mathrm{R}_{5}$ e $\mathrm{R}_{6}$.

\begin{tabular}{|c|c|c|c|}
\hline Tratamento & $\begin{array}{l}\text { Comprimento radicular } \\
\left(\mathrm{cm} \text { planta }^{-1}\right)\end{array}$ & $\begin{array}{l}\text { Superfície radicular } \\
\left(\mathrm{cm}^{2} \text { planta }^{-1}\right)\end{array}$ & $\begin{array}{l}\text { Diâmetro médio radicular } \\
\qquad(\mathrm{cm})\end{array}$ \\
\hline & \multicolumn{3}{|c|}{ Estádio $\mathrm{V}_{4}\left(3^{\mathrm{a}}\right.$ folha totalmente expandida $)$} \\
\hline Testemunha & $1301,8 \mathrm{a}$ & $197,3 \mathrm{a}$ & $0,047 b$ \\
\hline TS & $1239,7 \mathrm{a}$ & $194,2 \mathrm{a}$ & $0,049 \mathrm{a}$ \\
\hline \multirow[t]{2}{*}{ CV $(\%)$} & 2,4 & 2,9 & 1,3 \\
\hline & \multicolumn{3}{|c|}{ Estádio $\mathrm{R}_{5}$ (início do surgimento de botões florais) } \\
\hline Testemunha & $1364,11 \mathrm{a}$ & $208,63 a$ & $0,048 \mathrm{a}$ \\
\hline TS & $1347,80 \mathrm{a}$ & $208,06 \mathrm{a}$ & $0,049 \mathrm{a}$ \\
\hline $\mathrm{V}_{4}$ & $1328,66 \mathrm{a}$ & $197,16 \mathrm{a}$ & $0,047 \mathrm{a}$ \\
\hline $\mathrm{TS}+\mathrm{V}_{4}$ & $1310,36 \mathrm{a}$ & $193,94 a$ & $0,045 \mathrm{a}$ \\
\hline CV $(\%)$ & 3,7 & 5,0 & 6,1 \\
\hline \multicolumn{4}{|c|}{ Estádio $\mathrm{R}_{6}$ (florescimento pleno) } \\
\hline Testemunha & $1423,5 \mathrm{c}$ & $217,8 \mathrm{c}$ & $0,050 \mathrm{~b}$ \\
\hline TS & $1424,9 \mathrm{c}$ & $216,9 \mathrm{c}$ & $0,049 \mathrm{~b}$ \\
\hline $\mathrm{V}_{4}$ & $1457,1 \mathrm{bc}$ & $224,5 \mathrm{c}$ & $0,050 \mathrm{~b}$ \\
\hline $\mathrm{R}_{5}^{4}$ & $1630,4 \mathrm{a}$ & $287,9 \mathrm{a}$ & $0,055 \mathrm{a}$ \\
\hline $\mathrm{TS}+\mathrm{V}_{4}$ & $1562,8 \mathrm{ab}$ & $243,1 b c$ & $0,050 \mathrm{~b}$ \\
\hline $\mathrm{TS}+\mathrm{R}_{5}$ & $1637,7 \mathrm{a}$ & $266,7 \mathrm{ab}$ & $0,051 \mathrm{ab}$ \\
\hline $\mathrm{V}_{4}+\mathrm{R}_{5}$ & $1507,7 \mathrm{bc}$ & $221,5 \mathrm{c}$ & $0,050 \mathrm{~b}$ \\
\hline $\mathrm{TS}+\mathrm{V}_{4}+\mathrm{R}_{5}$ & $1401,0 \mathrm{c}$ & $216,4 \mathrm{c}$ & $0,050 \mathrm{~b}$ \\
\hline CV $(\%)$ & 3,4 & 4,9 & 4,0 \\
\hline
\end{tabular}

Médias seguidas da mesma letra na coluna, em cada época de avaliação, não diferem estatisticamente entre si pelo teste de Tukey a 5\% de probabilidade. Os tratamentos foram: Testemunha (sem aplicação de bioestimulante), TS (tratamento de semente), $\mathrm{V}_{4}$ (pulverização em $\mathrm{V}_{4}$ ), $\mathrm{R}_{5}$ (pulverização em $\mathrm{R}_{5}$ ), $\mathrm{TS}+\mathrm{V}_{4}$ (tratamento de semente + pulverização em $\mathrm{V}_{4}$ ), $\mathrm{TS}+\mathrm{R}_{5}$ (tratamento de semente + pulverização em $R 5$ ), $V_{4}+R_{5}$ (pulverização em $V_{4}+$ pulverização em $R_{5}$ ) e $T S+V_{4}+R_{5}$ (tratamento de semente + pulverização em $\mathrm{V}_{4}$ e $\mathrm{R}_{5}$ ).

Fonte: Elaboração dos autores.

Semelhante ao observado para o comprimento, a superfície radicular apresentou maiores valores nos tratamentos aplicação do produto em $\mathrm{R}_{5}$, ou em $\mathrm{TS}+\mathrm{R}_{5}$, porém, este último não diferindo estatisticamente do tratamento que recebeu aplicação em $\mathrm{TS}+\mathrm{V}_{4}$, na avaliação realizada em $\mathrm{R}_{6}$ (Tabela 4). O tratamento das sementes com o bioestimulante proporcionou diâmetro radicular das plantas de feijão 4,25\% superior ao da testemunha, na avaliação realizada no estádio $\mathrm{V}_{4}$. Na avaliação realizada no estádio $R_{5}$ não foi constatado efeito dos tratamentos, porém, em $\mathrm{R}_{6} \mathrm{o}$ tratamento que recebeu aplicação do bioestimulante via foliar em $\mathrm{R}_{5}$ apresentou diâmetro radicular significativamente maior, sem diferir do tratamento com aplicação em $\mathrm{TS}+\mathrm{R}_{5}$.
O tratamento de semente com bioestimulante não interferiu significativamente nas variáveis bioquímicas (aminoácidos totais, açucares solúveis totais e atividade da enzima nitrato redutase), avaliadas no estádio $V_{4}$ (Tabela 5). Houve efeito dos tratamentos no teor de aminoácidos totais apenas na avaliação realizada no estádio $\mathrm{R}_{6}$, sendo que o maior valor foi obtido com aplicação do bioestimulante via pulverização foliar no estádio $\mathrm{R}_{5}$, que foi $61 \%$ superior à testemunha. Quanto ao teor de açúcares solúveis totais, no estádio $\mathrm{R}_{5}$, observouse diminuição no conteúdo com a aplicação do biostimulante via tratamento de semente. No estádio $\mathrm{R}_{6}$, os tratamentos $\mathrm{TS}, \mathrm{V}_{4}+\mathrm{R}_{5}$ e $\mathrm{TS}+\mathrm{V}_{4}+\mathrm{R}_{5}$ foram $39,2 \%, 64,3 \%$ e $46,6 \%$ superiores à testemunha, respectivamente. Os teores de açúcares totais variam 
com o suprimento de carboidratos, alterações no metabolismo, ou ainda por diluição causada por aumento de diferentes partes da planta (QUILOT et al., 2004).

Resultados significativos para a atividade da nitrato redutase foram encontrados somente no estádio $\mathrm{R}_{6}$ (Tabela 5). Nesse trabalho, os tratamentos que proporcionaram maior área foliar apresentaram a menor atividade da enzima (Tabelas 3 e 5). Os resultados positivos observados podem ser devido à composição, concentração e proporção das substâncias presentes no bioestimulante. Reações como a glicólise, ciclo do ácido cítrico e a via pentose-fosfato (das quais originam os aminoácidos) podem ter sido beneficiadas e ter influenciado positivamente no metabolismo do feijoeiro. A aplicação do produto em mais de uma época $\left(\mathrm{TS}+\mathrm{V}_{4}\right.$ ou $\mathrm{TS}+\mathrm{R}_{5}$ ) proporcionaram melhores resultados das variáveis em questão, contradizendo relatos de Alleoni, Bosqueiro e Rossi (2000), que relataram que os efeitos dos produtos ocorreriam somente até a fase vegetativa.

Tabela 5. Teor de aminoácidos totais, conteúdo de açúcares solúveis totais e atividade da nitrato redutase no feijoeiro em função aplicação do bioestimulante, nos estádios $\mathrm{V}_{4}, \mathrm{R}_{5}$ e $\mathrm{R}_{6}$.

\begin{tabular}{|c|c|c|c|}
\hline Tratamento & $\begin{array}{c}\text { Teor de aminoácidos } \\
\text { totais } \\
\left(\mu \mathrm{g} \mathrm{mg}^{-1} \text { de MS }\right)\end{array}$ & $\begin{array}{c}\text { Teor de açúcares solúveis } \\
\text { totais } \\
\left(\mu \mathrm{g} \mathrm{mg} \mathrm{mg}^{-1} \mathrm{de}\right)\end{array}$ & $\begin{array}{c}\text { Atividade da nitrato } \\
\text { redutase } \\
\left(\mu \mathrm{M} \mathrm{h} \mathrm{h}^{-1}\right)\end{array}$ \\
\hline & \multicolumn{3}{|c|}{ Estádio $V_{4}\left(3^{\mathrm{a}}\right.$ folha totalmente expandida) } \\
\hline Testemunha & $12,9 \mathrm{a}$ & $54,4 \mathrm{a}$ & $92,1 \mathrm{a}$ \\
\hline TS & $13,2 \mathrm{a}$ & $56,2 \mathrm{a}$ & $104,1 \mathrm{a}$ \\
\hline \multirow[t]{2}{*}{$\mathrm{CV}(\%)$} & 38,7 & 26,1 & 19,1 \\
\hline & \multicolumn{3}{|c|}{ Estádio $\mathrm{R}_{5}$ (início do surgimento de botões florais) } \\
\hline Testemunha & $15,9 \mathrm{a}$ & $131,0 \mathrm{a}$ & $116,4 \mathrm{a}$ \\
\hline TS & $16,1 \mathrm{a}$ & $80,2 \mathrm{c}$ & $91,5 \mathrm{a}$ \\
\hline $\mathrm{V}_{4}$ & $12,7 \mathrm{a}$ & $113,2 \mathrm{ab}$ & $80,4 \mathrm{a}$ \\
\hline $\mathrm{TS}^{4}+\mathrm{V}_{4}$ & $17,5 \mathrm{a}$ & $106,0 \mathrm{~b}$ & $104,4 a$ \\
\hline \multirow[t]{2}{*}{ CV $(\%)$} & 20,6 & 9,0 & 20,0 \\
\hline & \multicolumn{3}{|c|}{ Estádio $\mathrm{R}_{6}$ (florescimento pleno) } \\
\hline Testemunha & $21,5 \mathrm{ab}$ & $83,6 \mathrm{e}$ & $46,6 \mathrm{ab}$ \\
\hline TS & $15,8 b$ & $122,6 \mathrm{ab}$ & $40,9 \mathrm{ab}$ \\
\hline $\mathrm{V}_{4}$ & $26,0 \mathrm{ab}$ & 86,1 de & $35,4 \mathrm{bc}$ \\
\hline $\mathrm{R}_{5}$ & $34,7 \mathrm{a}$ & $100,5 \mathrm{bcde}$ & $31,1 \mathrm{c}$ \\
\hline $\mathrm{TS}+\mathrm{V}_{4}$ & $13,5 b$ & $108,9 \mathrm{bcd}$ & $69,0 \mathrm{a}$ \\
\hline $\mathrm{TS}+\mathrm{R}_{5}$ & $20,8 \mathrm{ab}$ & $96,6 \mathrm{cde}$ & $53,6 \mathrm{ab}$ \\
\hline $\mathrm{V}_{4}+\mathrm{R}_{5}$ & $13,9 b$ & $137,4 a$ & $46,7 \mathrm{ab}$ \\
\hline $\mathrm{TS}^{4}+\mathrm{V}_{4}^{3}+\mathrm{R}_{5}$ & $16,9 b$ & $116,4 \mathrm{abc}$ & $66,9 \mathrm{ab}$ \\
\hline $\mathrm{CV}(\%)^{5}$ & 33,5 & 9,1 & 28,3 \\
\hline
\end{tabular}

Médias seguidas da mesma letra na coluna, em cada época de avaliação, não diferem estatisticamente entre si pelo teste de Tukey a 5\% de probabilidade. Os tratamentos foram: Testemunha (sem aplicação de bioestimulante), TS (tratamento de semente), $\mathrm{V}_{4}$ (pulverização em $\mathrm{V}_{4}$ ), $\mathrm{R}_{5}$ (pulverização em $\mathrm{R}_{5}$ ), $\mathrm{TS}+\mathrm{V}_{4}$ (tratamento de semente + pulverização em $\mathrm{V}_{4}$ ), $\mathrm{TS}+\mathrm{R}_{5}$ (tratamento de semente + pulverização em $\mathrm{R} 5$ ), $\mathrm{V}_{4}+\mathrm{R}_{5}$ (pulverização em $\mathrm{V}_{4}+$ pulverização em $\mathrm{R}_{5}$ ) e $\mathrm{TS}+\mathrm{V}_{4}+\mathrm{R}_{5}$ (tratamento de semente + pulverização em $\mathrm{V}_{4}$ e $\mathrm{R}_{5}$ ).

Fonte: Elaboração dos autores.

Apesar de alguns efeitos na nodulação, área foliar e crescimento radicular, não foram observados efeito nos componentes da produção e na produtividade de grãos do feijoeiro (Tabela 6). Oliveira, Pace e Rosolem (1998) e Alleoni, Bosqueiro e Rossi (2000) também não verificaram efeito da aplicação 
de bioestimulante, seja via tratamento de sementes ou via foliar, na produtividade do feijoeiro. Por outro lado, Cobucci e Wruck (2005) observaram incremento de $30 \%$ na produtividade, em relação à testemunha, quando aplicaram o bioestimulante no estádio $\mathrm{R}_{5}$. Abrantes et al. (2011) também constataram que aplicação do bioestimulante no estádio reprodutivo $\left(\mathrm{R}_{5}\right)$ porporcionou aumento no número de grãos por planta e produtividade de grãos do feijoeiro. Tais resultados indicam que a resposta da cultura a aplicação do bioestimulante depende não só da dose e época/forma de aplicação, mas também pode ser influenciada por outros fatores, como condição de cultivo e estresses aos quais as plantas são submetidas no momento da aplicação e nas fases subsequentes, como relatado por Alleoni, Bosqueiro e Rossi (2000) e Albrecht et al. (2012).

O teor de proteína bruta nos grãos do feijoeiro também não foi afetado pela aplicação do bioestimulante (Tabela 6). Albrecht et al. (2012) observaram apenas pequena tendência de aumento no teor de proteínas nos grãos de soja, com aplicação do bioestimulantes via foliar nos estádios vegetativo e reprodutivo.

Tabela 6. Número de vagens por planta, número de grãos por vagem, massa média de 100 grãos, massa de grãos por planta e teor de proteína nos grãos do feijoeiro em função da aplicação do bioestimulante.

\begin{tabular}{lccccc}
\hline Tratamento & $\begin{array}{c}\text { № de vagens/ } \\
\text { planta }\end{array}$ & $\begin{array}{c}\text { № de grãos/ } \\
\text { vagem }\end{array}$ & $\begin{array}{c}\text { Massa de } 100 \\
\text { grãos } \\
(\mathrm{g})\end{array}$ & $\begin{array}{c}\text { Massa de grãos/ } \\
\text { planta } \\
\left(\mathrm{g} \mathrm{planta}^{-1}\right)\end{array}$ & $\begin{array}{c}\text { Teor de proteína } \\
\text { nos grãos } \\
\left(\mathrm{g} \mathrm{kg}^{-1}\right)\end{array}$ \\
\hline Testemunha & $4,6 \mathrm{a}$ & $4,6 \mathrm{a}$ & $20,1 \mathrm{a}$ & $4,2 \mathrm{a}$ & $247,0 \mathrm{a}$ \\
$\mathrm{TS}$ & $4,5 \mathrm{a}$ & $4,5 \mathrm{a}$ & $17,9 \mathrm{a}$ & $3,6 \mathrm{a}$ & $247,8 \mathrm{a}$ \\
$\mathrm{V}_{4}$ & $4,5 \mathrm{a}$ & $4,8 \mathrm{a}$ & $19,4 \mathrm{a}$ & $4,1 \mathrm{a}$ & $253,3 \mathrm{a}$ \\
$\mathrm{R}_{5}$ & $4,3 \mathrm{a}$ & $4,8 \mathrm{a}$ & $20,2 \mathrm{a}$ & $4,2 \mathrm{a}$ & $251,3 \mathrm{a}$ \\
$\mathrm{TS}+\mathrm{V}_{4}$ & $4,8 \mathrm{a}$ & $4,9 \mathrm{a}$ & $16,5 \mathrm{a}$ & $4,0 \mathrm{a}$ & $261,4 \mathrm{a}$ \\
$\mathrm{TS}+\mathrm{R}_{5}$ & $4,2 \mathrm{a}$ & $4,5 \mathrm{a}$ & $17,0 \mathrm{a}$ & $3,1 \mathrm{a}$ & $263,4 \mathrm{a}$ \\
$\mathrm{V}_{4}+\mathrm{R}_{5}$ & $4,5 \mathrm{a}$ & $5,3 \mathrm{a}$ & $17,3 \mathrm{a}$ & $4,0 \mathrm{a}$ & $261,4 \mathrm{a}$ \\
$\mathrm{TS}+\mathrm{V}_{4}+\mathrm{R}_{5}$ & $3,9 \mathrm{a}$ & $5,0 \mathrm{a}$ & $16,6 \mathrm{a}$ & $3,2 \mathrm{a}$ & $239,1 \mathrm{a}$ \\
$\mathrm{CV}(\%)$ & 13,4 & 17,9 & 17,0 & 18,0 & 12,3 \\
\hline
\end{tabular}

Médias seguidas da mesma letra na coluna, em cada época de avaliação, não diferem estatisticamente entre si pelo teste de Tukey a 5\% de probabilidade. Os tratamentos foram: Testemunha (sem aplicação de bioestimulante), TS (tratamento de semente), $\mathrm{V}_{4}$ (pulverização em $\mathrm{V}_{4}$ ), $\mathrm{R}_{5}$ (pulverização em $\mathrm{R}_{5}$ ), $\mathrm{TS}+\mathrm{V}_{4}$ (tratamento de semente + pulverização em $\mathrm{V}_{4}$ ), $\mathrm{TS}+\mathrm{R}_{5}$ (tratamento de semente + pulverização em $\mathrm{R} 5$ ), $\mathrm{V}_{4}+\mathrm{R}_{5}$ (pulverização em $\mathrm{V}_{4}+$ pulverização em $\mathrm{R}_{5}$ ) e $\mathrm{TS}+\mathrm{V}_{4}+\mathrm{R}_{5}$ (tratamento de semente + pulverização em $\mathrm{V}_{4}$ e $\mathrm{R}_{5}$ ).

Fonte: Elaboração dos autores.

\section{Conclusões}

A aplicação do bioestimulante via foliar na fase vegetativa, ou início da reprodutiva, proporciona incrementos na nodulação, no crescimento radicular, no conteúdo de açúcares solúveis e aminoácidos totais e na atividade da nitrato redutase, porém, não interfe no crescimento da parte aérea e na produtividade da cultura do feijão.

\section{Agradecimentos}

À Fundação de Amparo à Pesquisa do Estado de São Paulo (FAPESP), pelo financiamento da pesquisa (Proc. 2008/05657-0) e concessão de bolsa à primeira autora (Proc. 2008/02835-4). Ao Conselho Nacional de Desenvolvimento Científico e Tecnológico (CNPq), pelo financiamento da pesquisa (Proc. 472551/2008-6) e concessão de bolsa de Produtividade em Pesquisa ao segundo autor. 


\section{Referências}

ABRANTES, F. L.; SÁ, M. E.; SOUZA, L. C. D.; SILVA, M. P.; SIMIDU, H. M.; ANDREOTTI, M.; BUZETTI, S.; VALÉRIO FILHO, W. V.; ARRUDA, N. Uso de regulador de crescimento em cultivares de feijão de inverno. Pesquisa Agropecuária Tropical, Goiânia, v. 41, n. 2, p. 148-154, 2011.

AIDAR, H.; KLUTHCOUSKI, J. Realidade versus sustentabilidade na produção do feijoeiro comum. In: KLUTHCOUSKI, J.; STONE, L. F.; AIDAR, H. Fundamentos para uma agricultura sustentável, com ênfase na cultura do feijoeiro. Santo Antônio de Goiás: Embrapa Arroz e Feijão, 2009. p. 21-33.

ALBRECHT, L. P.; BRACCINI, A. L.; ÁVILA, M. R.; BARBOSA, M. C.; RICCI, T. T.; ALBRECHT, A. J. P. Aplicação de biorregulador na produtividade do algodoeiro e qualidade de fibra. Scientia Agraria, Curitiba, v. 10, n. 3, p. 191-198, 2009.

ALBRECHT, L. P.; BRACCINI, A. L.; SCAPIM, C. A.; ÁVILA, M. R.; ALBRECHT, A. J. P.; RICCI, T. T. Manejo de biorregulador nos componentes de produção e desempenho das plantas de soja. Bioscience Journal, Uberlândia, v. 27, n. 6, p. 865-876, 2011.

ALBRECHT, L. P.; BRACCINI, A. L.; SCAPIM, C. A.; ÁVILA, M. R.; ALBRECHT, A. J. P. Biorregulador na composição química e na produtividade de grãos de soja1. Revista Ciência Agronômica, Fortaleza, v. 43, n. 4, p. 774-782, 2012.

ALLEONI, B.; BOSQUEIRO, M.; ROSSI, M. Efeito dos reguladores vegetais de Stimulate ${ }^{\circledR}$ no desenvolvimento e produtividade do feijoeiro (Phaseolus vulgaris L.). Publicatio UEPG - Ciências Exatas e da Terra, Ciências Agrárias e Engenharia, Ponta Grossa, v. 6, n. 1, p. 23-35, 2000.

ARCARO, T. F.; SOUZA, C. A.; SACHS, C.; COSTA, A. C.; FIGUEREDO, B. P.; PICCOLLA, C. D.; CARNIEL, G. Desempenho produtivo de dois genótipos de feijão sob influência de ácido giberélico. In: CONGRESSO NACIONAL DE PESQUISA DE FEIJÃO, 9., 2008, Campinas. Anais.... Campinas: IAC, 2008. 3 p. CDROM.

ÁVILA, M. R.; BARIZÃO, D. A. O.; GOMES, E. P.; FEDRI, G.; ALBRECHT, L. P. Cultivo de feijoeiro no outono/inverno associado à aplicação de bioestimulante e adubo foliar na presença e ausência de irrigação. Scientia Agraria, Curitiba, v. 11, n. 3, p. 221-230, 2010.

ÁVILA, M. R.; BRACCINI, A. L.; SCAPIM, C. A.; ALBRECHT, L. P.; TONIN, T. A.; STÜLP. M. Bioregulator application, agronomic efficiency, and quality of soybean seeds. Scientia Agricola, Piracicaba, v. 65 , n. 6, p. 604-612, 2008.
BALDO, R.; SCALON, S. P. Q.; ROSA, Y. B. C. J.; MUSSURY, R. M.; BETONI, R.; BARRETO, W. S. Comportamento do algodoeiro cultivar Delta Opal sob estresse hídrico com e sem aplicação de bioestimulante. Ciência e Agrotecnologia, Lavras, v. 33, p. 1804-1812, 2009. Número Especial.

BERTOLIN, D. C.; SÁ, M. E.; ARF, O.; FURLANI JUNIOR, E.; COLOMBO, A. S.; CARVALHO, F. L. B. M. Aumento da produtividade de soja com a aplicação de bioestimulantes. Bragantia, Campinas, v. 69, n. 2, p. 339-347, 2010.

CAMPOS, M. F.; ONO, E. O.; BOARO, C. S. F.; RODRIGUES, J. D. Análise de crescimento em plantas de soja tratadas com substâncias reguldoras. Biotemas, Florianópolis, v. 21, n. 3, p. 53-63, 2008.

CASTRO, G. S. A.; BOGIANI, J. C.; SILVA, M. G.; GAZOLA, E.; ROSOLEM, C. A. Tratamento de sementes de soja com inseticidas e um bioestimulante. Pesquisa Agropecuária Brasileira, Brasília, v. 43, n. 10, p. 1311-1318, 2008.

CASTRO, P. R. C. Utilização de reguladores vegetais na fruticultura, na horticultura e em plantas ornamentais. Piracicaba: ESALQ/DIBD, 1998. 92 p.

CASTRO, P. R. C.; SILVA, G. P.; CATO, S. C.; TAVARES, S. Ação de bioestimulantes em feijoeiro (Phaseolus vulgaris CV. IAC - Carioca Tybatã). Revista de Agricultura, Piracicaba, v. 79, n. 2, p. 215-226, 2004.

COBUCCI, T.; WRUCK, F. J. Resultados obtidos na área pólo de feijão no período de 2002 a 2004. Santo Antônio de Goiás: Embrapa Arroz e Feijão, 2005. 107 p. (Embrapa Arroz e Feijão. Documentos, 174).

COLL, J. B.; RODRIGO, G. N.; GARCIA, B. S.; TAMES, R. S. Fisiologia vegetal. Madrid: Ediciones Pirámide, 2001. $566 \mathrm{p}$.

DARIO, G. J. A.; MARTIN, T. N.; DOURADO NETO, D.; MANFRON, P. A.; BONNECARRÈRE, R. A. G.; CRESPO, P. E. N. Influência do uso de fitorregulador no crescimento da soja. Revista da Faculdade de Zootecnia, Veterinária e Agronomia, Uruguaiana, v. 12, n. 1, p. 6370, 2005.

DUBOIS, M.; GILLES, K. A.; HAMILTON, J. K.; REBERS P. A.; SMITH, F. Colorimetric method for determination of sugars and related substances. Analytical Chemistry, Washington, v. 28, n. 3, p. 350-356, 1956.

FANCELLI, A. L.; TSUMANUMA, G. M. Nitrogênio e enxofre nas culturas de milho e feijão. In: YAMADA, T.; ABDALLA, S. R. S.; VITTI, G. C. (Ed.). Nitrogênio e enxofre na agricultura brasileira. Piracicaba: IPNI Brasil, 2007. p. 445-486. 
FERNÁNDEZ, F.; GEPTS, P.; LÓPES, M. Etapas de desarrollo de la planta de frijol (Phaseolus vulgaris $L$.). Cali: Centro Internacional de Agricultura Tropical, 1986. $34 \mathrm{p}$.

FERREIRA, D. F. Sisvar: a computer statistical analysis system. Ciência e Agrotecnologia, Lavras, v. 35, n. 6, p. 1039-1042, 2011.

GONZALEZ-RIZZO, S.; CRESPI, M.; FRUGIER, F. The Medicago truncatula CRE1 cytokinin receptor regulates lateral root development and early symbiotic interaction with Sinorhizobium meliloti. The Plant Cell, Rockville, v. 18, n. 10, p. 2680-2693, 2006.

INFORZATO, R.; MIYASAKA, S. Sistema radicular do feijoeiro em dois tipos de solo do Estado de São Paulo. Bragantia, Campinas, v. 22, n. 38, p. 477-481, 1963.

JAWORSKI, E. G. Nitrate reductase assay in intact plant tissues. Biochemical and Biophysical Research Communications, Londres, v. 43, n. 6, p.1274-1279, 1971.

KABAT, E. A.; MAYER, M. M. Experimental immunochemistry. Springfield: C.C. Thomas, 1967. p. 560-563.

KEFFORD, N. P.; BROCKWELL, J.; ZWAR, J. A. The symbiotic synthesis of auxin by legumes and nodule bacteria and its role in nodule development. Australian Journal of Biological Sciences, East Melbourne, v. 13, n. 4, p. 456-467, 1960.

KLAHOLD, C. A.; GUIMARÃES, V. F.; ECHER, M. M.; KLAHOLD, A.; ROBINSON, L. C.; BECKER, A. Resposta da soja (Glycine max (L.) Merrill) à ação de bioestimulante. Acta Scientiarum. Agronomy, Maringá, v. 28, n. 2, p. 179-185, 2006.

KUDOYAROVA, G. R.; FARKHUTDINOV, R. G.; VESELOV, S. Y. Comparison of the effects of nitrate and ammonium forms of nitrogen on auxin content in roots and the growth of plants under different temperature conditions. Plant Growth Regulation, Dordrecht, v. 23, n. 3, p. 207-208, 1997.

LIEVENS, S.; GOORMACHTIG, S.; DEN HERDER, J.; CAPOEN, W.; MATHIS, R.; HEDDEN, P.; HOLSTERS, M. Gibberellins are involved in nodulation of Sesbania rostrata. Plant Physiology, Rockville, v. 139, n. 4, p. 1366-1379, 2005.

MATHESIUS, U. Auxin: at the root of nodule development? Functional Plant Biology, Victoria, v. 35, n. 8, p. 651-668, 2008.

MURRAY, J. D.; KARAS, B. J.; SATO, S.; TABATA, S.; AMYOT, L.; SZCZYGLOWSKI, K. A cytokinin perception mutant colonized by Rhizobium in the absence of nodule organogenesis. Science, Washington, v. 315, n. 1, p. 101-104, 2007.

OLIVEIRA, R. F.; PACE, L.; ROSOLEM, C. A. Produção e estado nutricional do feijoeiro em função da aplicação de um promotor de crescimento. Científica, São Paulo, v. 26, n. 1-2, p. 203-212, 1998.

PERET, B.; SWARUP, R.; JANSEN, L.; DEVOS, G.; AUGUY, F.; COLLIN, M.; SANTI, C.; HOCHER, V.; FRANCHE, C.; BOGUSZ, D.; BENNETT, M.; LAPLAZE, L. Auxin influx activity is associated with Frankia infection during actinorhizal nodule formation in Casuarina glauca. Plant Physiology, Rockville, v. 144, n. 4, p. 1852-1862, 2007.

QUILOT, B.; GENARD, M.; KERVELLA, J.; LESCOURRET, F. Analysis of genotypic variation in fruit flesh total sugar content via an ecophysiological model applied to peach. Theory Applyed for Genetic, Berlin, v. 109, n. 2, p. 440-449, 2004.

SILVA, J. I. C.; PEREIRA, F. R.; CRUZ, S. C.; PEREIRA, M. R. R.; FREITAG, E. E.; ARAÚJO, H. B.; VILLAS BÔAS, R. L. Uso de estimulantes de crescimento radicular associado a doses de fósforo na cultura do feijoeiro. Agrarian, Dourados, v. 2, n. 5, p. 47-62, 2009.

SPAEPEN, S.; VANDERLEYDEN, J.; REMANS, R. Indole-3-acetic acid in microbial and microorganismplant signaling. FEMS Microbiology Reviews, Londres, v. 31, n. 4, p. 425-448, 2007.

TAIZ, L.; ZEIGER, E. Fisiologia vegetal. Porto Alegre: Artmed, 2009. 848 p.

TENNANT, D. A. A test of a modified line intersect method of estimating root length. Journal of Ecology, Oxford, v. 63, n. 3, p. 9 95-1001, 1975.

THEUNIS, M.; KOBAYASHI, H.; BROUGHTON, W. J.; PRINSEN, E. Flavonoids, NodD1, NodD2, and nodbox NB15 modulate expression of the $\mathrm{y} 4 \mathrm{wEFG}$ locus that is required for indole-3-acetic acid synthesis in Rhizobium sp. strain NGR234. Molecular Plant-Microbe Interactions, Saint Paul, v. 17, n. 10, p. 1153-1161, 2004.

VIEIRA, E. L.; CASTRO, P. R. C. Ação de bioestimulante na cultura do feijão (Phaseolus vulgaris L.). In: FANCELLI, A. L.; DOURADO NETO, D. Feijão irrigado: tecnologia e produtividade. Piracicaba: Departamento de Produção Vegetal/ESALQ, 2003. p. 73-100.

Ação de bioestimulante na germinação de sementes, vigor das plântulas, crescimento radicular e produtividade de soja. Revista Brasileira de Sementes, Londrina, v. 23, n. 2, p. 222-228, 2001. 